\title{
Sustainability Adoption Trend Analysis
}

\author{
Simon Walter Miller, Paolo W. Pecorario, and Lisa M. Ulan \\ The Pennsylvania State University, University Park, Pennsylvania, 16802, USA \\ \{swm154, pwp5155, Imu5012\}@psu. edu
}

\begin{abstract}
The sustainability trend in the automotive market has been analyzed. A dataset of cars was elicited from select companies that have increased their market share in the United States automotive market over the past decade. In the first part, a linear regression model is developed to evaluate how the market share is influenced by key vehicle characteristics, and in particular, to evaluate the role of sustainability in that analysis. For the second part, game theory has been applied to see how market dynamics change in relation to sustainability moves of two competitors. The third part uses technology forecasting techniques to suggest which technology to invest. The results of the paper show that, in the long term, sustainability will be a significant factor in determining a company's market share. Investing in manufacturing processes that reduce the cost of battery systems can support the competitiveness of hybrid vehicles but so too can investing in research and development to reduce the energy density gap between gasoline and batteries.
\end{abstract}

Keywords: sustainability, game theory, technology forecasting.

\section{Introduction}

As a society, we are becoming more aware of non-renewable resource depletion. Future generations are discussing the utility and potential of sustainable resources in the current market. Behavior regarding sustainability is extremely complex as it deals with factors such as politics, beliefs versus actions, and socio-economic status. Several set-backs in industry exist in regard to producing sustainable products such as lack of clarity on how to implement sustainability in industry, and possibly most important, when to release a sustainable product into the market. Industry needs to know how the market will behave and react.

Increased awareness and education levels impact sustainable behavior; however, this is an ongoing research topic. Our objective is to research sustainability trends in terms two automotive competitors to see how the market reacts. This will be done through demand modeling and predicting market share of certain vehicles and their attributes, game theory, and technology forecasting of a sustainable vehicle attribute and how it pertains to investment. This paper is divided into background information, the perception of sustainability, a game theory application, battery technology forecasting, and conclusions. 


\section{Background}

The Environmental Protection Agency (EPA) has been categorizing sustainability for some time and has designated carbon dioxide $(\mathrm{CO} 2)$ as a "... greenhouse gas that traps the earth's heat and contributes to the potential for global warming" 1. There are many contributors to this effect from the automotive industry including the development, manufacture, transportation, use, and infrastructure required to maintain a fleet of vehicles both in the U.S. and across the globe. Omar 2 performed an energy audit of the amount of energy and CO2 generated during an energy audit of a typical light passenger vehicle over ten years and concluded that end-user use corresponds with approximately $90 \%$ of the total energy and greenhouse gas emitted during the life of a vehicle.

Manufacturing and transportation costs are a difficult metric to reduce in the abstract so a quick investigation into why material and consumer use contribute so heavily to these sustainable metrics is explored. The energy audit by [2] showed a typical breakdown of materials by weight for a typical sedan. The standout is that mild steel contributes $44 \%$ of the total weight of the vehicle. There is a trend in manufacturing to incorporate composites and plastic to reduce vehicle weight and to increase fuel economy by allowing for more aerodynamic shapes to be designed. The metalworking required to generate steel and the machine it is energy intensive and can relate to global effects.

The weight of the vehicle has a direct correlation with energy consumption for both manufacturing and consumer use. Data collected by 2] demonstrate the relationship between vehicles' energy consumption per kilometer of travel and fuel economy versus curb weight, and greenhouse emission versus energy consumption for a variety hybrid and non-hybrid vehicles. It suggests that decreases in weight of the vehicle as well as increases in fuel economy can lead to more sustainable vehicles.

Vehicles are a commodity and their influence on sustainability can be controlled by consumers through the purchase of vehicles that are lightweight and have good fuel economy. There are many other factors affecting the automotive industry to address sustainability, and the reader is encouraged to read through [3] for an excellent review discussing design for sustainability in the automotive industry. In the end, consumers play a large role in determining the viability of a product and so Sect. 3 discusses a method to determine if sustainability is important or even relevant to consumers during their vehicle purchasing decision.

\section{Perception of Sustainability}

How has the consumer-perceived value of sustainability changed across time? What is to be expected in the near future?

We first focus attention on the customer perceived value of sustainability, how this has changed across time, and how it is expected to be in the near future. The focus is on the value that sustainability has for a customer, how sustainability contributes to make a specific product more desirable, and how sustainability 
increasing the value of a product for a customer. The analysis presented here is based on the automotive market, but the principles can be implemented in many other different fields, and for different kind of products.

\subsection{Methodology}

To understand if and how sustainability contributes value for the customer, a benchmark was defined and data were collected. We focus on two car makers that have been able to increase their market share in the last decade, based on trends collected from 4, namely Toyota and Honda. These two car makers have increased from 9.1 to $14.1 \%$ for Toyota, and from 6.5 to $9.6 \%$ for Honda in this time. They are considered in our analysis as two companies that seem to be trending together and thereby making them direct competitors. A sample dataset is collected of their vehicles, including a hybrid and a gasoline vehicle. The combination of hybrid and non-hybrid is used to determine if there are synergies for the automaker via a halo effect. Two models of cars from each manufacturer have been taken into account in the dataset, the Toyota Prius, Toyota Corolla, Honda Civic Hybrid, and Honda Accord.

Since these two companies have increased in market share, they may have successful features that other companies do not have. A regression model is developed for the analysis as (11), where the dependent variable $(y)$ is the market share. The regression is a linear model with two-factor interactions.

$$
y(x)=\beta_{0}+\sum_{i=1}^{n} \beta_{i} x_{i}+\sum_{i=1}^{n} \sum_{j>i}^{n} \beta_{i j} x_{i} x_{j}
$$

The market share depends on many variables including primary (e.g., price, reputation, and fuel economy), secondary (e.g., style), etc. A subset of characteristics was chosen that could be readily gathered by consumers online. The independent variables included are as follows:

- Year - the model year of the vehicle.

- Manufacturer's Suggested Retail Price (MSRP) - nominal price of the car.

- Curb weight - total mass of the vehicle with standard equipment. It can be viewed as a surrogate metric for car dimension, perceived safety, sustainability, and reliability of a vehicle.

- Combined Fuel Economy - in miles per gallons, a well know index of efficiency performance of the engine, which can be used as an estimation of fuel consumption and expenditure for a particular kind of car.

- Greenhouses Gases Emitted - in tons per year, a direct metric of sustainability of a car. It includes carbon dioxide, methane, and nitrous oxide.

These variables are some of the most common attributes that are accessible to a consumer when evaluating a vehicle. These variables are advertised by the car makers and the metrics are well known. Other variables can be elicited for this problem, but these five attributes are simple and are common to consumers when describing a vehicle purchasing decision. These attributes were collected from [5] and [6] for 2001 through 2012 when available. 


\section{$3.2 \quad$ Results}

A regression analysis was performed using best subset analysis, a method that examines all possible combinations of predictor variables using (1) as the model, with centered predictors. The model with the highest coefficient of determination $\left(R^{2}\right)$ is selected - the generated model has an $R^{2}$ of 0.916 with 43 samples. Model coefficients and statistical measures is shown in Table 1 .

Table 1. Regression Model Output

\begin{tabular}{lcrcrr}
\hline Predictor & Centroid & Estimate & $\begin{array}{c}\text { Standard } \\
\text { Error }\end{array}$ & t-Statistic & p-value \\
\hline Constant $\left(\beta_{0}\right)$ & - & 1.448700 & 0.095081 & 15.237 & $3.20 \mathrm{E}-16$ \\
Year & 2006.91 & 0.067261 & 0.027279 & 2.466 & 0.019221 \\
MSRP & 20781.70 & -0.000179 & 0.000085 & -2.124 & 0.041512 \\
Weight & 2864.37 & 0.004038 & 0.001299 & 3.108 & 0.003935 \\
MPG & 34.465 & -0.121992 & 0.089362 & -1.365 & 0.181727 \\
Greenhouse & 4.602 & -0.528704 & 0.756184 & -0.699 & 0.489494 \\
Year*MSRP & - & -0.000006 & 0.000005 & -1.227 & 0.228865 \\
Year*Greenhouse & - & -0.097961 & 0.043220 & -2.267 & 0.030311 \\
MSRP*MGP & - & 0.000071 & 0.000017 & 4.115 & 0.000253 \\
MSRP*Greenhouse & - & 0.000767 & 0.000187 & 4.095 & 0.000268 \\
Weight*Greenhouse & - & -0.002912 & 0.000954 & -3.053 & 0.004540 \\
\hline
\end{tabular}

The model incorporates interactions which make interpretations more complex, but we can observe that the model suggests several features relevant to sustainability and describe them here briefly. We note that Greenhouse has a strong negative coefficient and, when coupled with Year, MSRP, and Weight, suggest that market share may decrease if it is not addressed. This is consistent with a greener perspective that has been touted in recent years. $M P G$ also has a general trend of negative impact on market share implying that consumers are concerned with fuel economy in the current economy; improvement in fuel economy is expected through time. MSRP when coupled with Year has a negative coefficient, suggesting that decreases in prices over time should increase market share. MSRP when coupled with Greenhouse has a positive coefficient suggesting that greenhouses gases emitted are a metric related to engine performance or luxury, i.e., more performance tends to yield more emissions. $M P G$ coupled with $M S R P$ has a positive coefficient suggesting that as fuel economy increases, the more the customer is willing to pay. This can be viewed as a basic metric of sustainability; the customer may not be directly interested in environmental sustainability, but may likely be interested in saving money with fuel economy.

\subsection{Discussion}

The linear regression model suggests that sustainability has increased customer perceived value throughout years based on market share and a few consumer 
predictors. This result supports push for competitors to develop more sustainable vehicles by investing in sustainable energy systems and features. The regression describes overall market trends, but how does a company position itself to gain more market share? Game theory, described next, is a tool that can help.

\section{Game Theory}

How do you expect the market dynamics to change in relation to sustainability moves of the two competitors?

A game theory matrix is a game that has two players that have a finite strategy set with a specified number of elements, and the payoffs are posed in an $S_{1} \times S_{2}$ matrix. Player 1 and player 2 independently and simultaneously choose a strategy $s_{1} \in S_{1}, s_{2} \in S_{2}$, respectively and receive their designated payoff, $u_{i}\left(s_{1}, s_{2}\right)$. Toyota and Honda are competitors in the car industry and will be represented as two players in our game.

\subsection{Methodology}

A model was used to predict market share for the two companies, Honda and Toyota. The model includes the same dependent variables as in Sect. 3] and the dependent variable output predicted by the model is the percentage of the market share of a hypothetical vehicle. The sustainability aspect of this model is the amount of greenhouse gases emitted. The purpose of this game is to see how market dynamics (or market share) change in relation to sustainability moves, and in particular greenhouse gases emitted from different vehicle designs.

\section{$4.2 \quad$ Results}

Different hypothetical designs are created for each company, and a regression model is used to predict the market share of that vehicle for each company. The application of the game theory model is presented using the scenario in which both companies use the same model to investigate interactions between one another. The method can also be applied independently to look at individual strengths.

Five car designs were chosen for each company based upon the five attributes: Year, MSRP, Weight, MPG, and Greenhouse. These car designs can be viewed in Table 2 .

The Nash Equilibrium is Toyota T2, Honda H5. This indicates that if Toyota were to choose their T2 vehicle design, Honda should choose their H5 vehicle design, and vice versa. This is the optimal scenario for each company as neither company has an incentive to deviate. The game can become more complicated by inserting external factors such as competition for customers, customer loyalty, and so on. 
Table 2. Hypothetical scenario vehicle builds for Toyota and Honda

\begin{tabular}{cccccccc}
\hline \multicolumn{2}{c}{ Scenario Model } & Year & MSRP & Weight & MPG & Greenhouse & Market Share \\
\hline T1 & Toyota & 2012 & 26900 & 3042 & 50 & 2.97 & 0.962 \\
T2 & Toyota & 2012 & 25500 & 3042 & 50 & 2.97 & 1.459 \\
T3 & Toyota & 2012 & 27900 & 3000 & 51 & 2.96 & 0.582 \\
T4 & Toyota & 2012 & 26900 & 3000 & 51 & 2.95 & 0.841 \\
T5 & Toyota & 2012 & 28000 & 2900 & 55 & 2.90 & 0.976 \\
\hline H1 & Honda & 2012 & 24200 & 2853 & 44 & 3.37 & 0.181 \\
H2 & Honda & 2012 & 23000 & 2853 & 44 & 3.37 & 0.752 \\
H3 & Honda & 2012 & 25800 & 2800 & 48 & 3.50 & 0.349 \\
H4 & Honda & 2012 & 24200 & 2800 & 48 & 3.50 & 0.495 \\
H5 & Honda & 2012 & 27500 & 2750 & 50 & 3.60 & 0.990 \\
\hline
\end{tabular}

\subsection{Discussion}

Based upon these games, we can see that in the in the long term sustainability should increase market share, but in the short term it does not. If the company is to invest long term, a strategy can emerge that requires development time and cost now, but will have dividends later. What technology will provide the most "green" alternative? Or will better hedge against competition? A forecasting technique is now used to determine which technology might bolster a company's green appeal.

\section{Technology Forecast}

What is one of the technologies you are able to justify investing into? How do you expect to see the performance (and may be cost) to change of this technology?

An issue that Hybrid electric vehicles have is that their competition (gasoline powered automobiles) uses a very energy dense fuel $(\sim 12800 \mathrm{Wh} / \mathrm{kg})$ to provide power and range. Battery technology has yet to progress at a pace with Moore's Law 7] which states that many technologies have been doubling their performance every 18 months due to fundamental chemistry inherent to a battery's inner workings [8].

Certainly there must be a technology that can achieve a high energy density so that batteries can compete with gasoline engines. Technology forecasting is a method that uses historical data to predict future characteristics of useful technological machines, procedures, techniques, protocols, etc. The primary use of the method is to analyze the current state-of-the-art and determine, through a regression analysis, how the technology will perform in the near future.

The energy densities of various battery technologies are forecast and analyzed to determine if investing in a particular technology will become competitive or if a new technology should be invested. The following sections describe the methodology of forecasting and their interpretations. 


\subsection{Methodology}

The technology life-cycle describes the commercial impact of a product through research and development through profitability. The "shape" of the curve describing a technology is often referred to as an S-curve because of its slow growth through its conception and introduction, its steady growth through product maturity, and its slowed growth at the end of its life-cycle at which point a newer technology assumes a similar pattern. This shape can be parameterized as (2) where: $f(t)$, performance of a metric over time $t ; f_{0}$, performance offset time for introduction; $S$, scaling factor for total growth; $\alpha$, rate of growth; $\beta$, shifting parameter.

$$
f(t)=f_{0}+S \frac{\exp (\alpha t+\beta)}{1+\exp (\alpha t+\beta)}
$$

Equation (2) is essentially a logistic regression with a scaling term $S$ and an offset term $f_{0}$. The parameters are estimated using a nonlinear regression routine that uses historical data over time for each technology metric of interest. The data used in the analysis was taken from [9] for various primary batteries including: Zn-Carbon, $\mathrm{Mg} / \mathrm{MnO} 2, \mathrm{Zn} / \mathrm{HgO}$, Alkaline-MnO2, Li/MnO2, Li/SO2, $\mathrm{Li} / \mathrm{SOCI} 2$, and Zn/Air. Details about the batteries, their characteristics, applications, and cost can be found in 9 .

\subsection{Results}

The nonlinear regression model described in (2) was implemented and the results are shown in Table 3. The table shows the regression coefficients (appropriate units are assumed) and the predicted performance of the technology in the year 2013 and 2020.

Table 3. Results of the regression analysis of forecasting various battery technologies

\begin{tabular}{lrrrrrr}
\hline Technology & $f_{0}$ & $S$ & $\alpha$ & $\beta$ & $f(2013)$ & $f(2020)$ \\
\hline Zn-Carbon & 55.609 & 41.695 & 0.506 & -1001.820 & 97.3 & 97.3 \\
$\mathrm{Mg} / \mathrm{MnO} 2$ & 80.217 & 37.114 & 0.090 & -177.560 & 116.9 & 117.1 \\
$\mathrm{Zn} / \mathrm{HgO}$ & 38.189 & 101.846 & 0.061 & -120.145 & 136.1 & 137.4 \\
Alkaline-MnO2 & 62.235 & 102.268 & 0.473 & -936.427 & 164.5 & 164.5 \\
$\mathrm{Li} / \mathrm{MnO} 2$ & 145.335 & 87.388 & 0.551 & -1093.350 & 232.7 & 232.7 \\
$\mathrm{Li} / \mathrm{SO} 2$ & 127.233 & 161.985 & 0.316 & -622.261 & 289.2 & 289.2 \\
$\mathrm{Li} / \mathrm{SOCI} 2$ & 17.748 & 305.175 & 0.505 & -996.407 & 322.2 & 322.9 \\
Zn/Air & 77.890 & 301.797 & 0.179 & -352.650 & 379.4 & 379.6 \\
\hline
\end{tabular}

\subsection{Discussion}

The linear regression indicates that each technology appears to be saturated with $\mathrm{Zn} /$ Air being the largest at $\sim 379 \mathrm{Wh} / \mathrm{kg}$. Zn/Air does, however, suffer 
from environmental conditions and would most likely deteriorate during use in outdoor settings such as driving. $\mathrm{Li} / \mathrm{SOCl} 2$ is the next highest with $\sim 323$ $\mathrm{Wh} / \mathrm{kg}$, which is still quite high when compared to current lithium-ion secondary batteries that have an energy density of $\sim 130 \mathrm{Wh} / \mathrm{kg}$ 9. Li/SOCl2 currently cost quite a bit more than conventional battery systems which may diminish its utility. However, the regression performed during technology forecasting does not incorporate questions of cost - it only describes the performance over time.

\section{Conclusions}

In this paper, the role of sustainability in the consumer perceived value has been analyzed. From the linear regression model we can hypothesize that sustainability has increased customer perceived value throughout the years. The regression ignores contingency variables such as fuel prices and economic crisis, but as a simple model it captures the effect of sustainability in relation to market share quite well. This result of the model could leads competitors to develop more sustainable vehicles by investing in sustainable energy systems and features. Investment in "greener" technology is justified by a higher market share over years. For what concerns technology investment justification and performance expectation, two possible solutions can be under-taken: either invest in manufacturing enhancements of this battery type or to begin research and development in a different technology. Further research should focus on the impact of contingency variables and how they affect consumer purchasing habits.

\section{References}

1. Automobile Emissions: An Overview. Washington, DC: US Environmental Protection Agency. EPA publication 400-F-92-007 (1994)

2. Omar, M.A.: The Automotive Body Manufacturing Systems and Processes. Wiley, Chichester (2011)

3. Mayyas, A., Qattawi, A., Omar, M., Shan, D.: Design for sustainability in automotive industry: A comprehensive review. Renewable and Sustainable Energy Reviews 16(4), 1845-1862 (2012)

4. WardsAuto. The Information Center For And About The Global Auto Industry. Penton Media Web. (May 01, 2013), http://www.wardsauto.com

5. AOL Autos. Web. (May 01, 2013), www.autos.aol.com

6. Environmental Protection Agency. Web. (May 01, 2013), www.epa.gov/greenvehicles/Index.do

7. Jogaleker, A.: Moore's Law and battery technology: no dice. Scientific American (2013)

8. Schlachter, F.: No Moore's Law for batteries. Proceedings of the National Academy of Sciences 110(14), 5273-5273 (2013)

9. Linden, D., Reddy, T.B.: Handbook of Batteries. McGraw-Hill, New York (2002) 